\title{
Application of a Reservoir-Type Calcitriol Transdermal Patch in Dairy Cattle
}

\author{
Norio YAMAGISHI ${ }^{1,3) *}$, Toru NAMIOKA ${ }^{1)}$, Norimoto OKURA ${ }^{4)}$, Shigeru SATO ${ }^{1,3)}$, Danil KIM ${ }^{3)}$, \\ Kazuhisa FURUHAMA ${ }^{2,3)}$ and Yoshihisa NAITO ${ }^{1)}$ \\ ${ }^{1)}$ Departments of Veterinary Clinical Medicine and ${ }^{2)}$ Veterinary Basic Medicine, Faculty of Agriculture, Iwate University, Morioka, Iwate \\ 020-8550, ${ }^{3)}$ United Graduate School of Veterinary Sciences, Gifu University, Gifu 501-1193 and ${ }^{4)}$ Biei Veterinary Clinical Center, \\ Kamikawa Chuo Agricultural Mutual Aid Association, Biei, Hokkaido 071-0214, Japan
}

(Received 25 January 2009/Accepted 17 February 2009)

\begin{abstract}
Our objective was to evaluate the effects of a reservoir-type calcitriol (5 mg/animal) transdermal patch on plasma calcitriol and calcium (Ca) concentrations in dairy cattle. A group of six heifers received three different types of patches: an encapsulated reservoir solution containing calcitriol alone (CAL), calcitriol with dodecylamine (CAL+D), or vehicle (CONT). The patches were applied to the skin of the tail for duration of 2 days at intervals of at least 3 weeks. Cattle that received CAL or CAL+D showed significant increases in plasma calcitriol and $\mathrm{Ca}$ concentrations on day 2 and days 2 and 3, respectively. The areas under the plasma concentration-time curve (AUC) values for plasma calcitriol and $\mathrm{Ca}$ in the $\mathrm{CAL}$ and CAL $+\mathrm{D}$ groups increased significantly compared to the CONT group. The data of this study describe evidence of measurable transdermal absorption of exogenous calcitriol from a patch and its sufficient biological action to elevate plasma Ca concentrations.
\end{abstract}

KEY WORDS: calcitriol, calcium, cattle, reservoir-type transdermal patch.

Vitamin $\mathrm{D}_{3}\left(\mathrm{VD}_{3}\right)$, which is metabolized in the liver to 25-hydroxyvitamin $\mathrm{D}_{3}$ and subsequently to 1,25-dihydroxyvitamin $\mathrm{D}_{3}$ (calcitriol) in the kidneys [6], is commonly used as a prophylaxis for parturient hypocalcemia in dairy cows [8]. Calcitriol is the most active form of $\mathrm{VD}_{3}$ involved in the regulation of calcium $(\mathrm{Ca})$ metabolism; however, it is difficult to accurately determine a feasible time course for the administration of calcitriol due to difficulties in predicting the actual calving date. Therefore, opinions vary as to whether the intramuscular or intravaginal administration of calcitriol in dairy cows prevents hypocalcemia $[5,16-18$, $20]$.

Within the veterinary field, the topical application of a wide range of pharmaceutical agents has been reported to be a useful alternative to traditional delivery routes [12]. For example, compared to parenteral administration, drug delivery via the skin has many benefits. Specifically, topical application is a non-invasive procedure that supplies a constant level of the drug within a narrow therapeutic window (thus minimizing the risk of adverse effects or the reduction of efficiency) and avoids gastrointestinal disturbances and hepatic first-pass effects [3]. Previously, we reported that the topical delivery of a calcitriol liquid formulation onto the ventral root skin of the tail elicits incremental increases in plasma calcitriol and subsequent increases in plasma $\mathrm{Ca}$ in dairy cattle [13]. Unfortunately, this delivery method is unlikely to be suitable for clinical use; the liquid formulation was applied to cattle in a supine recumbent position under xylazine sedation.

A reservoir-type transdermal patch is convenient method

\footnotetext{
* Correspondence to: Yamagishi, N., Department of Veterinary Clinical Medicine, Faculty of Agriculture, Iwate University, Morioka, Iwate 020-8550, Japan.
}

e-mail: yamagisi@iwate-u.ac.jp for the systemic delivery of human medicines. With the patch, drug permeability can be controlled over a long period relative to topical delivery [19]. To our knowledge, however, little information is available on the use of transdermal calcitriol patches in cattle. Here, we examined the effects of experimentally fabricated reservoir-type transdermal patches containing calcitriol ( $5 \mathrm{mg}$ /animal) on plasma calcitriol and $\mathrm{Ca}$ concentrations in dairy cattle. Additionally, the additive effects of dodecylamine, an enhancer used to increase drug permeability via the skin [1], were also investigated.

Six healthy, non-pregnant Jersey heifers (age, 12-23 months; body weight, $135-311 \mathrm{~kg}$ ) were used in this investigation. Grass hay $(0.4 \% \mathrm{Ca}$ and $0.3 \%$ phosphate of dietary dry matter) and water were provided ad libitum throughout the study. Subjects were treated with one of three types of patches containing a $500 \mu l$ reservoir solution made of 10 $\mu \mathrm{g} / \mu l$ calcitriol in vehicle (99\% ethanol; CAL), $10 \mu \mathrm{g} / \mu l$ calcitriol with $10 \mu \mathrm{g} / \mu l$ dodecylamine in vehicle (CAL+D), or vehicle alone as a control (CONT). Treatments were assigned according to a randomized block design. Treatment intervals were at least 3 weeks in length. During the experiments, each patch was applied once to the ventral root skin of the tail and bandaged with elastic adhesive tape (Sylkytex-E, Alcare Co., Ltd., Japan). The patch was removed 2 days later. The dosages and/or concentrations of calcitriol and dodecylamine were chosen based on the results of previous studies examining the topical administration of calcitriol [13] and the efficacy of testosterone patches [10], respectively. The study protocol and the experimental design were approved by the Iwate University Laboratory Animal Care and Use Committee.

Crystalline calcitriol (powder form) was provided by Mercian Corporation (Tokyo, Japan). Dodecylamine was 


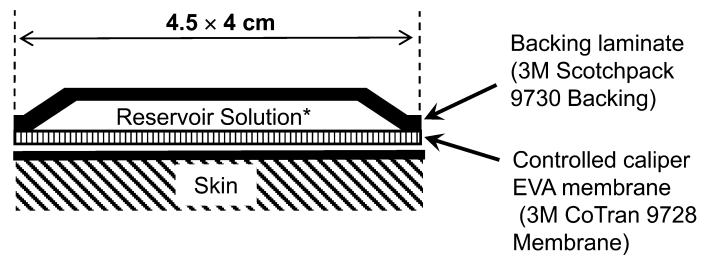

Fig. 1. Schema of a reservoir-type transdermal patch. * The reservoir solution were made of $10 \mu \mathrm{g} / \mu l$ calcitriol in vehicle ( $99 \%$ ethanol; CAL), $10 \mu \mathrm{g} / \mu l$ calcitriol with $10 \mu \mathrm{g} / \mu l$ dodecylamine in vehicle $(\mathrm{CAL}+\mathrm{D})$, or vehicle alone as a control (CONT).

purchased from Sigma Chemical Co. (St. Louis, MO, U.S.A.). The backing laminate (3M Scotchpack 9730 Backing) and controlled caliper ethylene vinyl acetate (EVA) membrane (3M CoTran 9728 Membrane) were gifts from $3 \mathrm{M}$ Health Care Ltd. (Tokyo). The patch was fabricated by encapsulating the reservoir solutions as described above within a shallow compartment molded from the backing laminate and covered with the controlled caliper EVA membrane (Fig. 1). In brief, both the backing laminate and controlled caliper EVA membrane were cut to a size of $4.5 \times 4$ $\mathrm{cm}$. The backing laminate was placed on the EVA membrane and then heat-sealed on three sides. The reservoir solution was dispersed into the device using a micropipette. That device was heat-sealed to close the final side, thus ensuring that none of the solution would leak out of the patch. Each patch was then kept in a sealed aluminum pouch at $4^{\circ} \mathrm{C}$ until application to minimize the loss of ethanol.

Heparinized blood samples were drawn from the jugular vein of each heifer immediately before application of the patches (day 0 ) and again at $0.25,0.5,1,2,3$, and 5 days later. The day of application was designated as day 0 . The blood was centrifuged immediately to separate plasma for the determination of calcitriol and $\mathrm{Ca}$ concentrations. Plasma specimens were frozen at $-50^{\circ} \mathrm{C}$ until analyzed. Plasma calcitriol concentrations were measured by radioimmunoassay $\left(1,25(\mathrm{OH})_{2} \mathrm{D}\right.$ RIA kit, Immunodiagnostic Systems Ltd., UK) and plasma $\mathrm{Ca}$ concentrations were measured using the orthocresolphthalein complexone method [2].

All numerical data are expressed as means \pm standard deviations. One-way repeated measures analysis of variance (ANOVA), followed by Dunnett's tests for multiple comparisons, was performed to analyze changes in plasma calcitriol and $\mathrm{Ca}$ concentrations. Specifically, each value was compared with the baseline value (day 0) for each patch. Differences in plasma calcitriol and Ca concentrations among the three patches were compared using oneway ANOVA and Tukey-Kramer multiple comparison tests. The areas under the plasma concentration-time curves (AUCs) for plasma calcitriol and $\mathrm{Ca}$ concentrations from 0 to $120 \mathrm{hr}$ (days 0 to 5) were calculated using the linear trapezoidal rule. One-way ANOVA and Tukey-Kramer multiple comparison tests were performed to compare differences
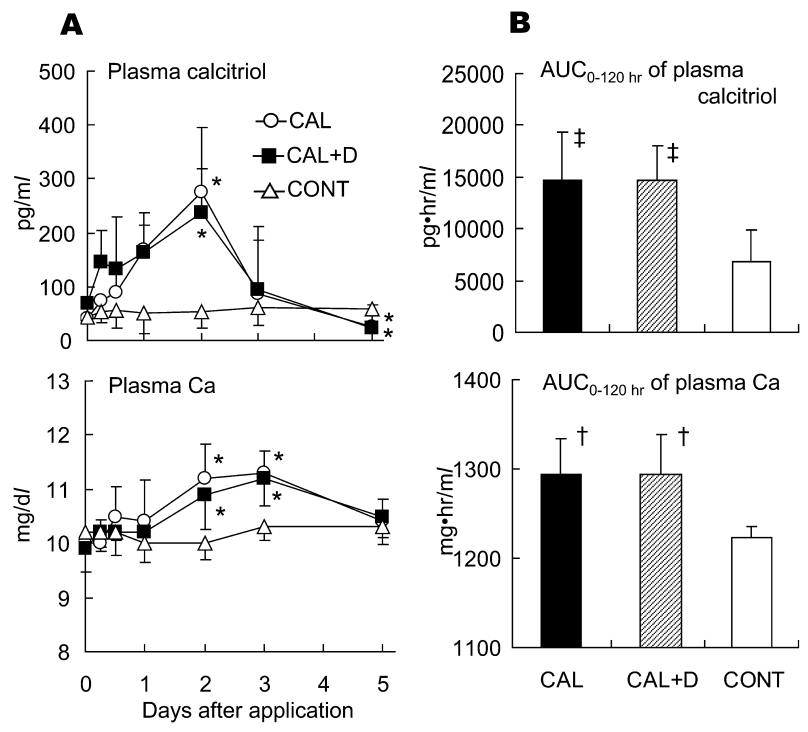

Fig. 2. Changes in plasma calcitriol and $\mathrm{Ca}$ concentrations during the experiments $(\mathrm{A})$ and $\mathrm{AUC}_{0-120 \mathrm{hr}}$ of plasma calcitriol and $\mathrm{Ca}$ concentrations (B) in the CAL, CAL $+\mathrm{D}$ or CONT groups. Significant difference from CONT at the same day $\left(\mathrm{n}=6,{ }^{*} p<0.05\right.$, Tukey-Kramer multiple comparison tests). Significant difference from CONT $(n=6, \dagger p<0.05, \ddagger p<0.01$, Tukey-Kramer multiple comparison tests).

in the $\mathrm{AUC}_{0-120 \mathrm{hr}}$ among the three patches. The threshold for statistical significance was $p<0.05$.

Although erythema developed on the area of skin that contacted the patches in all groups (including the CONT group on day 2), this reaction disappeared within a few days.

Changes in plasma calcitriol and $\mathrm{Ca}$ concentrations are shown in Fig. 2A. Compared to the baseline value (day 0), no change in plasma calcitriol or $\mathrm{Ca}$ concentration was observed in the CONT group throughout the experimental period. In the CAL group, mean plasma calcitriol concentrations increased significantly from $41.3 \mathrm{pg} / \mathrm{ml}$ on day 0 to 169.6 and $274.7 \mathrm{pg} / \mathrm{m} l$ on days 1 and $2(p<0.05)$, respectively. After day 2, calcitriol levels dropped. In the CAL $+\mathrm{D}$ group, mean plasma calcitriol concentrations increased from $69.3 \mathrm{pg} / \mathrm{m} l$ on day 0 to $236.6 \mathrm{pg} / \mathrm{m} l$ on day $2(p<0.05)$, and fell thereafter. Compared to the CONT group, cattle exposed to either $\mathrm{CAL}$ or $\mathrm{CAL}+\mathrm{D}$ exhibited significantly higher mean plasma calcitriol concentrations on day 2 (274.7 pg/m $l$ in CAL and $236.6 p \mathrm{~g} / \mathrm{m} l$ in CAL $+\mathrm{D}, p<0.05$ ) and lower concentrations on day $5(25.0 \mathrm{pg} / \mathrm{ml}$ in CAL and $22.1 \mathrm{pg} / \mathrm{m} l$ in $\mathrm{CAL}+\mathrm{D}, p<0.05)$. Likewise, mean plasma $\mathrm{Ca}$ concentrations increased significantly in both groups on days 2 and 3 (approximately $11 \mathrm{mg} / \mathrm{d} l, p<0.05$ ) compared to the CONT group (10.0 to $10.3 \mathrm{mg} / \mathrm{d} l$ ).

The $\mathrm{AUC}_{0-120 \mathrm{hr}}$ values for plasma calcitriol and $\mathrm{Ca}$ concentrations are shown in Fig. 2B. Both $\mathrm{CAL}$ and $\mathrm{CAL}+\mathrm{D}$ groups displayed significantly higher $\mathrm{AUC}_{0-120 \mathrm{hr}}$ values for plasma calcitriol $(p<0.01)$ and $\mathrm{Ca}(p<0.05)$ concentrations compared to the CONT group. 
To the best of our knowledge, this study is the first to report evidence of measurable transdermal absorption of exogenous calcitriol from a patch. We observed elevated plasma calcitriol concentrations (approximately $250 \mathrm{pg} / \mathrm{m} l$ ) on day 2 and an increased $\mathrm{AUC}_{0-120 \mathrm{hr}}$ value for plasma calcitriol within the CAL and CAL $+\mathrm{D}$ groups. Calcitriol increases plasma $\mathrm{Ca}$ concentrations by facilitating intestinal absorption [4]. In cows, Hove et al. [10] reported that maximal increase in plasma $\mathrm{Ca}$ occurred when plasma calcitriol reached $250 \mathrm{pg} / \mathrm{ml}$ after calcitriol administration (intramuscular or oral administration of calcitriol or its analogues). In our study, we noted that cattle given CAL or $\mathrm{CAL}+\mathrm{D}$ showed elevations in plasma $\mathrm{Ca}$ concentrations (approximately $11 \mathrm{mg} / \mathrm{d} l$ ) on days 2 and 3 . In addition, the $\mathrm{AUC}_{0-120}$ $\mathrm{hr}$ values appear to be identical to findings in cattle treated with a topical liquid formulation of calcitriol [17]. These results demonstrated that calcitriol absorbed via the skin exerts sufficient biological action.

Meanwhile, plasma calcitriol concentrations decreased on day 5 in both the CAL and CAL $+\mathrm{D}$ groups. Previous investigations have also reported that the treatment of parturient cows with exogenous calcitriol causes prolonged decreases in plasma calcitriol concentrations approximately one week after intramuscular injection [20]. These findings are likely the result of endogenous calcitriol synthesis inhibition via 1- $\alpha$-hydroxylase due to exogenous calcitriol administration $[11,14]$.

Dodecylamine is a typical unsaturated fatty amine that has been shown to increase the skin permeability of various drugs dispensed through a patch (e.g., testosterone) $[1,10]$. Ethanol, which was used as a vehicle in this study, is also reported to increase skin permeability in a wide range of drugs in humans and animals, in both in vivo and in vitro systems [9]. The mutual permeability-enhancing effect between dodecylamine and ethanol has been reported in a patch with testosterone [10]. However, in this study, no significant difference in $\mathrm{AUC}_{0-120 \mathrm{hr}}$ for plasma calcitriol or $\mathrm{Ca}$ concentration was noted between the $\mathrm{CAL}$ and $\mathrm{CAL}+\mathrm{D}$ groups. These results suggest that skin permeability of calcitriol was not improved by the addition of dodecylamine. It is also possible that the skin permeability of calcitriol in 99\% ethanol has already reached its threshold, despite the addition of dodecylamine.

In conclusion, our results suggest that a patch procedure using calcitriol is easy, versatile, and reliable. Specifically, we found that plasma calcitriol concentrations increase to a physiologically acceptable level (approximately $250 \mathrm{pg} / \mathrm{m} l$ ) [7] and that plasma $\mathrm{Ca}$ is maintained at a reasonable concentration (approximately $11 \mathrm{mg} / \mathrm{d} /$ ) on days 2 and 3 post-application. For clinical use, however, further studies are necessary to improve skin permeability of calcitriol via changes in the device and the selection of appropriate enhancers and vehicles. Because percutaneous absorption may decrease with age [15], future studies are required to determine the rate of percutaneous absorption in adult cows.

ACKNOWLEDGMENTS. The authors thank Dr. A.
Watanabe (Pharmaceuticals \& Chemicals Division, Mercian Corporation) for supplying calcitriol and Mr. Y. Miyazaki (Drug Delivery System Project Department, 3M Health Care Limited) for the supplying 3M Scotchpack 9730 Backing and 3M CoTran 9728 Membranes. We also thank Mr. S. Akasaka, Mr. G. Abe, and Mr. H. Chida (University Research Farms, Iwate University) for their diligent care of the animals.

\section{REFERENCES}

1. Aungst, B. J., Blake, J. A. and Hussain, M. A. 1990. Contributions of drug solubilization, partitioning, barrier disruption, and solvent permeation to the enhancement of skin permeation of various compounds with fatty acids and amines. Pharm. Res. 7: 712-718.

2. Connerty, H. V. and Briggs, A. R. 1966. Determination of serum calcium by means of orthocresolphthalein complexone. Am. J. Clin. Pathol. 45: 290-296.

3. Finnin, B. C. and Morgan, T. M. 1999. Transdermal penetration enhancers: applications, limitations, and potential. $J$. Pharm. Sci. 88: 955-958.

4. Garabedian, M., Tanaka, Y., Holick, M. F. and DeLuca, H. F. 1974. Response of intestinal calcium transport and bone calcium mobilization to 1,25-dihydroxyvitamin D3 in thyroparathyroidectomized rats. Endocrinology 94: 1022-1027.

5. Gast, D. R., Horst, R. L., Jorgensen, N. A. and DeLuca, H. F. 1979. Potential use of 1,25-dihydroxycholecalciferol for prevention of parturient paresis. J. Daily Sci. 62: 1009-1013.

6. Horst, R. L. and Reinhardt, T. A. 1983. Vitamin D metabolism in ruminants and its relevance to the periparturient cow. $J$. Daily Sci. 66: 661-678.

7. Hove, K., Horst, R. L. and Littledike, E. T. 1983. Effect of $1 \alpha-$ hydroxyvitamin D3, 1,25-dihydroxyvitamin D3, 1,24,25-trihydroxyvitamin D3, and 1,25,26-trihydroxyvitamin D3 on mineral metabolism and 1,25-dihydroxyvitamin D concentrations in dairy cows. J. Daily Sci. 66: 59-66.

8. Julien, W. E., Conrad, H. R., Hibbs, J. W. and Crist, W. L. 1977. Milk fever in dairy cows. VIII. Effect of injected vitamin D3 and calcium and phosphorus intake on incidence. J. Daily Sci. 60: 431-436.

9. Kim, D.D., Kim, J.L. and Chien, Y.W. 1996. Mutual hairless rat skin permeation-enhancing effect of ethanol/water system and oleic acid. J. Pharm Sci. 85: 1191-1195.

10. Kim, M.K., Zhao, H., Lee, C.H. and Kim, D.D. 2001. Formulation of a reservoir-type testosterone transdermal delivery system. Int. J. Pharm. 219: 51-59.

11. Littledike, E. T., Engstrom, G. W. and Sachs, M. 1986. Sequential sampling and analysis of renal hydroxylase activities of cattle given 1- $\alpha$-hydroxyvitamin D3. J. Dairy Sci. 69: 990-997.

12. Mills, P.C. and Cross, S.E. 2006. Transdermal drug delivery: basic principles for the veterinarian. Vet. J. 172: 218-233.

13. Namioka, T., Yamagishi, N., Okura, N., Akasaka, S., Abe, T., Chida, H., Sato, S., Naito, Y. 2008. Transdermal absorption of 1,25-dihydroxyvitamin D3 in cattle. Jpn. J. Vet. Clinics 31: 15 (in Japanese with English abstract).

14. Naito, Y., Goff, J. P., Horst, R. L., Reinhardt, T. A. 1989. Effects of continuous administration of 1,25-dihydroxyvitamin D3 on plasma minerals and unoccupied mucosal 1,25-dihydroxyvitamin D3 receptor concentrations. J. Dairy Sci. 72: 2936-2941. 
15. Ngawhirunpat, T., Hatanaka, T., Katayama, K., Yoshikawa, H., Kawakami, J. and Adachi, I. 2002. Changes in electrophysiological properties of rat skin with age. Biol. Pharm. Bull. 25: $1192-1196$.

16. Okura, N., Yamagishi, N., Naito, Y., Kanno, K. and Koiwa, M. 2004. Vaginal absorption of $1,25(\mathrm{OH})_{2} \mathrm{D}_{3}$ in cattle. J. Daily Sci. 87:2416-2419.

17. Okura, N., Yamagishi, N., Naito, Y., Muranaka, K., Sato, S. and Koiwa, M. 2007. Vaginal absorption of 1,25-dihydroxyvitamin D3 in preparturient cows. J. Jpn. Vet. Med. Assoc. 60: 430-433 (in Japanese with English abstract).
18. Okura, N., Yamagishi, N., Naito, Y. and Koiwa, M. 2007. Dose response to vaginal administration of 1,25-dihydroxyvitamin $\mathrm{D}_{3}$ to cows. Vet. J. 174: 203-205.

19. Riviere, J.E. and Papich, M.G. 2001. Potential and problems of developing transdermal patches for veterinary applications. Adv. Drug Deliv. Rev. 50: 175-203.

20. Yamagishi, N., Ayukawa, Y., Lee, I., Oboshi, K. and Naito, Y. 2005. Calcium metabolism in cows receiving an intramuscular injection of 1,25-dihydroxyvitamin D3 combined with prostaglandin $\mathrm{F}_{2 \alpha}$ closely before parturition. J. Vet. Sci. 6: 165-167. 